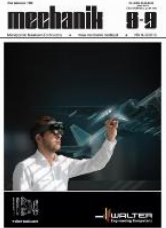

Authors: Marcin Żółkoś, Marek Krok, Janusz Porzycki, Janusz Świder, Marek Grabowy

Title of article: „Zautomatyzowane stanowisko do diagnozowania procesów szlifowania” (“Grinding processes automated diagnostic test stand")

Mechanik, Vol. 91, No. 8-9 (2018): pages 747-750

DOI: https://doi.org/10.17814/mechanik.2018.8-9.122

\title{
Grinding processes automated diagnostic test stand
}

\section{Zautomatyzowane stanowisko do diagnozowania procesów szlifowania}

\author{
MARCIN ŻókKOŚ \\ MAREK KROK \\ JANUSZ PORZYCKI \\ JANUSZ ŚWIDER \\ MAREK GRABOWY *
}

Presented is the automated measuring test stand based on the modified Haas VF-2YT machining center. That allows conducting experimental research of conventional and assisted with workpiece ultrasonic oscillations grinding processes (UAG). Respective measurement paths and automated measurement data acquisition process during the experimental research was discussed. Particular notice was given to grinding force components measurement system. KEYWORDS: automated test stand, grinding, measurement of forces in grinding process, UAG

In the face of machining continuously developed, hard and brittle materials, conventional grinding techniques are appearing less efficient in modern times. Hence hybrid grinding processes in which ultrasonic vibration may be one of the additional source of energy that assists machining process through tool or workpiece oscillations, are more often used [1].

The most widespread hybrid process in abrasive machining is grinding assisted with tool oscillations - as evidenced by the availability of production machines adapted to this type of machining. However, for ultrasonic assisted grinding (UAG) with a vibrating workpiece, there are no ready-made production solutions, although the method offers more kinematic variations compared to grinding assisted with tool oscillations [2].

Conducted research indicates advantageous influence of introducing workpiece ultrasonic oscillations to conventional grinding process on tool life, surface quality and grinding force values [1-3]. Therefore, it is necessary to continue experimental studies designed to determine optimal UAG technological parameters and their influence on the quality indicators of this process, including surface roughness and dimensional-shape accuracy. The final result of this studies should be the development of mathematical models describing dependencies in the grinding process and

\footnotetext{
* Mgr inż. Marcin Żółkoś (markos@prz.edu.pl), mgr inż. Marek Krok (mkrok@prz.edu.pl), prof. nadzw. dr hab. inż. Janusz Porzycki (jpor@prz.edu.pl) - Wydział Budowy Maszyn i Lotnictwa Politechniki Rzeszowskiej; dr inż. Janusz Świder (swider@cerel.pl), dr inż. Marek Grabowy (grabowy@cerel.pl) - Instytut Energetyki, Oddział Ceramiki CEREL
}

allowing for input parameters selection based on the expected output effects.

In order to obtain credible results, it is necessary to conduct adequate amount of measurements for many input parameters (grinding wheel peripheral speed, feed rate, grinding depth, vibration amplitude, vibration direction, etc.). It significantly expands experimental design which impose automation of measuring data acquiring and analyzing process to ensure its efficiency. Test stand that allows conducting research of grinding process with and without assisting it with workpiece ultrasonic oscillations was designed and constructed for this purpose.

The complete test stand consisted of a CNC machining center with an integrated ultrasonic vibration inducing system assisting the grinding process and three measuring systems (fig. 1).

The first system was used to measure the vibration amplitude of the workpiece. It allowed for sonotrode evaluations and adequate selection of waveguide operation parameters in order to attain defined amplitude value. Second system served for acquisition of the force values that occurs in grinding process with or without ultrasonic assistance. The third system was responsible for measuring the surface roughness obtained after each machining pass [4].

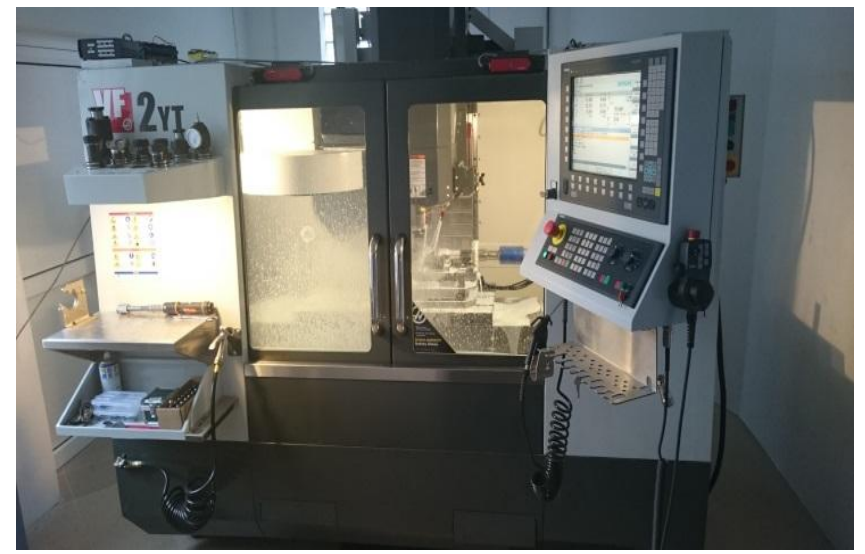

Fig. 1. Grinding processes automated diagnostic stand [4] 


\section{CNC machining center}

The Haas VF-2YT vertical machining center was used as the basis for the test stand, prepared for the needs of the PBS2/B6/17/2013 project [4], for studies the grinding processes assisted with workpiece oscillations. In the original version of the machine tool it was not possible to assist the machining processes with ultrasonic vibrations, mainly due to the limitations of the Haas control system, which did not allow to adjust its configuration to the needs of controlling the ultrasonic generator. An additional obstacle was the lack of software sharedby the manufacturer for creating PLC programs and adding additional operating screens. Therefore, the creation of a test stand for examination of ultrasonic assisted grinding processes required a series of machining center modifications.

They were mainly based on the replacement of the control system for the Sinumerik $840 \mathrm{D}$ sl system with all its consequences (including replacement of the control cabinet, drive modules, central unit, inputs and outputs of the PLC and control panel). In addition, to enable the automatic control of the ultrasonic generator via the machine NC system directly from the part programs, it was necessary to implement changes in the PLC program by adding additional auxiliary functions $\mathrm{M}$ (controlling the generator on and off and switching on and off the transducer cooling) and operating screens, enabling determination of individual generator parameters [4].

Control programs written for the needs of experimental studies consist of a series of cyclically repeated machine movements whiletechnological parameters changes. In order to optimize the preparation of such programs, own machining and measurement cycles have been developed to simplify programming of the test stand:

- SET_TECH - a cycle that sets the appropriate values for grinding speed and feed rate, switches on ultrasonic vibrations, coolant supply and transducer cooling,

- UNSET_TECH - transducer control cycle (vibration deactivation with transducer cooling remaining) without interfering with technological parameters,

- MARKER - marking cycle, which controls the signal (using auxiliary functions M93 and M94) derived from the PLC for numbering consecutivemeasuring passes in the TDMS file,

- CUTTING - surface grinding cycle for any grinding depth, including sparking passes and using the PLC output (controlled by auxiliary functions M91 and M92) to start and end data acquisition from a single measurement pass.

Additionally, an own postprocessor (using user cycles) has been implemented that automates the process of creating technology programs based on a determined experimental design, also taking into account necessary breaks for surface roughness measurements.

\section{Ultrasonic vibration inducing system}

The most important part of the whole test stand is the ultrasonic vibration inducingsystem (fig. 2), which consists of the following elements:

- Generator - a device generating high frequency alternating current for supplying the transducer. In this case, a universal generator was used dedicated for use in ultrasonic welding processes. Manufactured by MP Interconsulting, the WG-1000 W model has a maximum power of $1000 \mathrm{~W}$ and a working range from 20 to $100 \mathrm{kHz}$ [4-6].

- Transducer - converting the alternating current of the resonant frequency of the transducer's mechanical elements through the executive element (piezoelectric rings) to intense mechanical vibrations. The appropriate shape of the executive block and the steel reactance block ensure on the output from the transducer the maximum amplitude, which depending on the number of rings, can have a value from several to a dozen or so micrometers. In this research stand, a piezoelectric transducer conforming to the Branson $502 / 932 \mathrm{R}$ model with the manufacturer's designation MPI5020S-6PS was used, equipped with six piezoelectric rings, in which the reactance block is made of 304 stainless steel, and the executive block is made of Ti6Al4V titanium alloy [4-6].

- Amplifier (booster, first stage converter) - an optional modifier of a oscillating wave that amplifies or reduces the amplitude of vibration by a constant coefficient and is usually a fastening element. A booster with a gain factor of $1: 1.5$ was used on the test stand $[4,6]$.

- Sonotrode (second stage converter) - an executive element in contact with the workpiece, which transmits vibration energy to it. The sonotrode should have a wave characteristic, the form of which corresponds to the vibration of the longitudinal wave of the waveguide. However, the resonant frequency of the vibrations should be as close as possible to the resonance frequency of the transducerbooster system. The sonotrode project must also anticipate that the desired form of vibration should be as low mode of a wave as possible, so that the sonotrode can work with less energy introduced into the system. In order to determine the resonant frequency of the sonotrode, a modal analysis of the predicted shape using the finite element method should be performed $[4,6]$.

Real charateristic of the waveguide elements, despite careful manufacturing, deviate slightly from their nominal characteristic. This is due to the non-homogeneous material structure or uneven mass distribution in the waveguide. Therefore, in order to prepare the vibration inducing system, it is necessary to adjust the operating parameters of the ultrasonic generator for proper cooperation with a given waveguide [4].

An important issue is also the material from which the individual elements of the ultrasonic vibration inducing system are made. Construction materials used for waveguide construction should be characterized by high mechanical strength, possibly low acoustic impedance and low density $[4,6]$.

The Ti6Al4V titanium alloy was chosen as the material for making the amplifier due to the low acoustic impedance of this material and its high durability. Sonotrodes were made of aluminum 7075 , which has the best ratio of acoustic impedance and machinability compared to other materials [4].

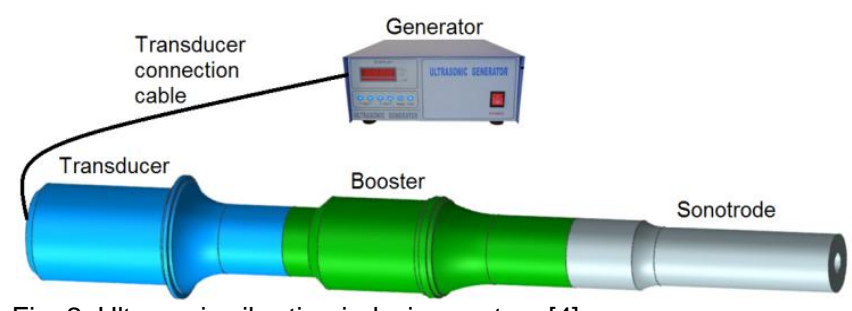

Fig. 2. Ultrasonic vibration inducing system [4]

\section{System for measuring forces}

For measuring the cutting forces occurring in the ultrasonic assisted grinding process, a dynamometer based on four piezoelectric sensors type 9601A3110000 by Kistler was used. Piezoelectric transducers, converting the forces acting on them to a voltage proportional to their value, allow to measure cutting forces in three axes perpendicular to one another: $X, Y$ and $Z[7]$.

The use of four sensors forced the use of electric charges adder to obtain from twelve input signals one signal at the output for each axis [4]. Three output signals from the adder were transferred to the industrial electric charges amplifier type 5073A311, converting signals from 
piezoelectric sensors to the industrial standard of $\pm 10 \mathrm{~V}$ with a proportional value [7]. Then signals from forces in the $X, Y$ and $Z$ axes were transferred to the National Instruments USB6009 Data Acquisition device and saved using the LabVIEW SignalExpress software.

After developing the entire system and before conducting the actual research, the indications of the measured values of the dynamometer were calibrated. This process was carried out using a calibrated bow dynamometer [4]. The described force measuring system is shown in fig. 3 .

In order to improve the measurements, at a very large number of them, a system was designed and created for controlling measurements of grinding force from the level of the technological program. For the needs of this solution, additional two signals were derived from the PLC controller, controlled by auxiliary functions $\mathrm{M}$ :

- M91 - switching on the first signal - start of the machining pass

- M92 - switching off the first signal - end of machining pass,

- M93 - switching on the second signal - sign 1 in the numbering of machining passes,

- M94 - switching off the second signal - sign 0 in the numbering of machining passes.

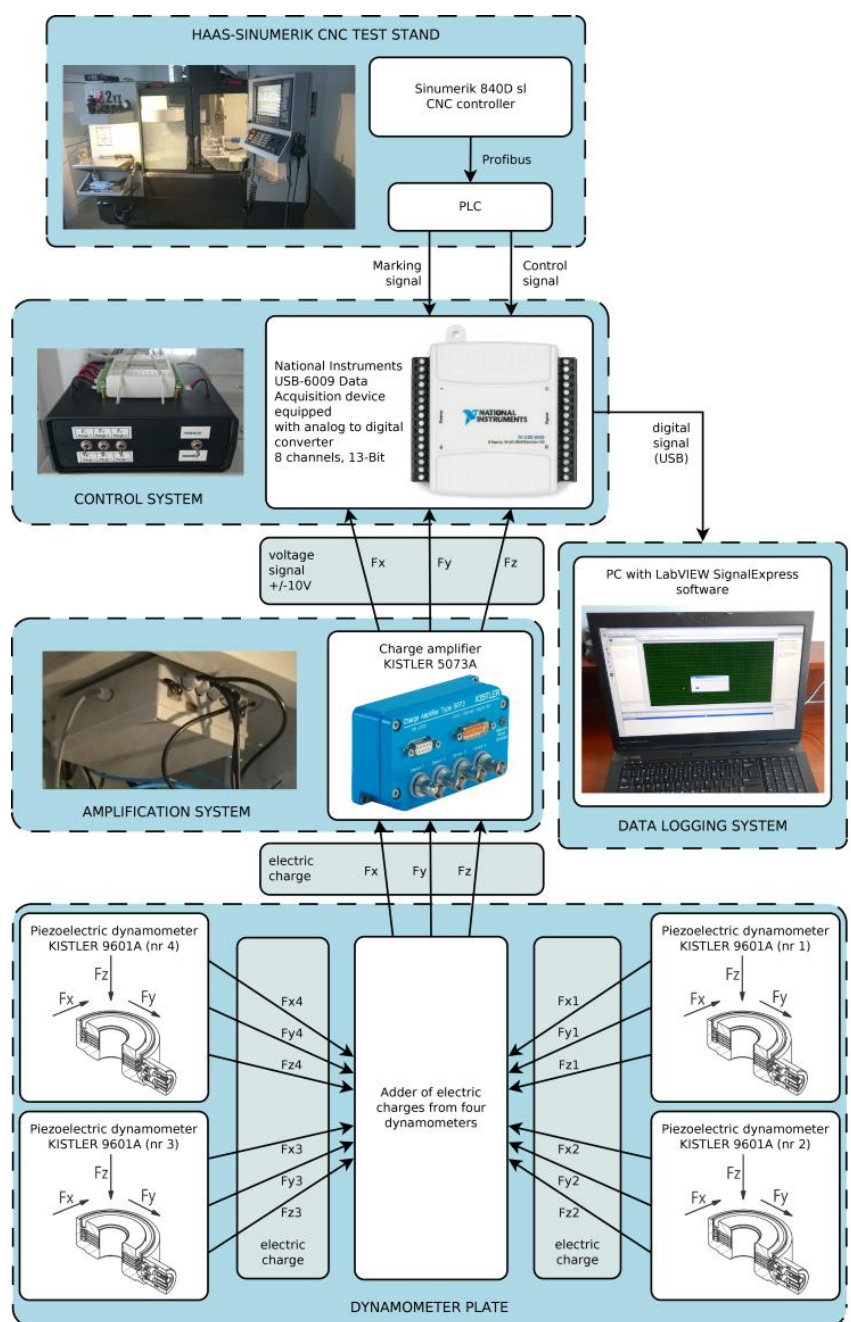

Fig. $\overline{3}$. Block diagram of the system for measuring forces in the grinding process [4]

The first signal was used to automatically switch the dynamometer from the standby mode to the measurement mode, and thus to specify the intervals in which material removal occurred. This was possible because the start and end $M$ functions were placed in the program just before and after the machining passes. This solution allows for a more accurate analysis of the results due to the clearly marked which ranges of recorded signals of the grinding force, are to be considered. It also enabled the automation of the data processing process by means of a properly written computer algorithm.

The second signal was used for numbering the consecutive machining passes, which were performed with various technological parameters. Each machining pass was assigned a binary number recordedusing 8 bits in the plot of logged cutting forces $(0-0 \mathrm{~V}, 1-5 \mathrm{~V})$, which allowed for a precise connection of the measured course of forces with the machining parameters at which it was registered, because each number was matched with the process input parameters saved in the form of a unified number.

\section{System for measuring vibration amplitude}

To carry out the research, it is necessary to know the amplitude and frequency of vibrations of the workpiece embedded in the waveguide, for the sonotrode used in a given experimental design. With a view to measuring these values, the system shown in fig. 4 has been developed.

This system is based on an EU05 eddy current sensor from Micro-Epsilon with active temperature compensation and a controller with an adaptive plate dedicated for this sensor. Together, these elements form a non-contact displacement measurement system called eddyNCDT 3300 from the same company, allowing to measure displacement in the range of $0.5 \mathrm{~mm}$ with an accuracy of $1 \mu \mathrm{m}$. The next element was the GW Instek GDS-1000A-U digital oscilloscope - used to record an analog signal from the eddyNCDT 3300 controller, which saves this data to a CSV file on the SD memory card. These data are later processed to determine the desired quantities.

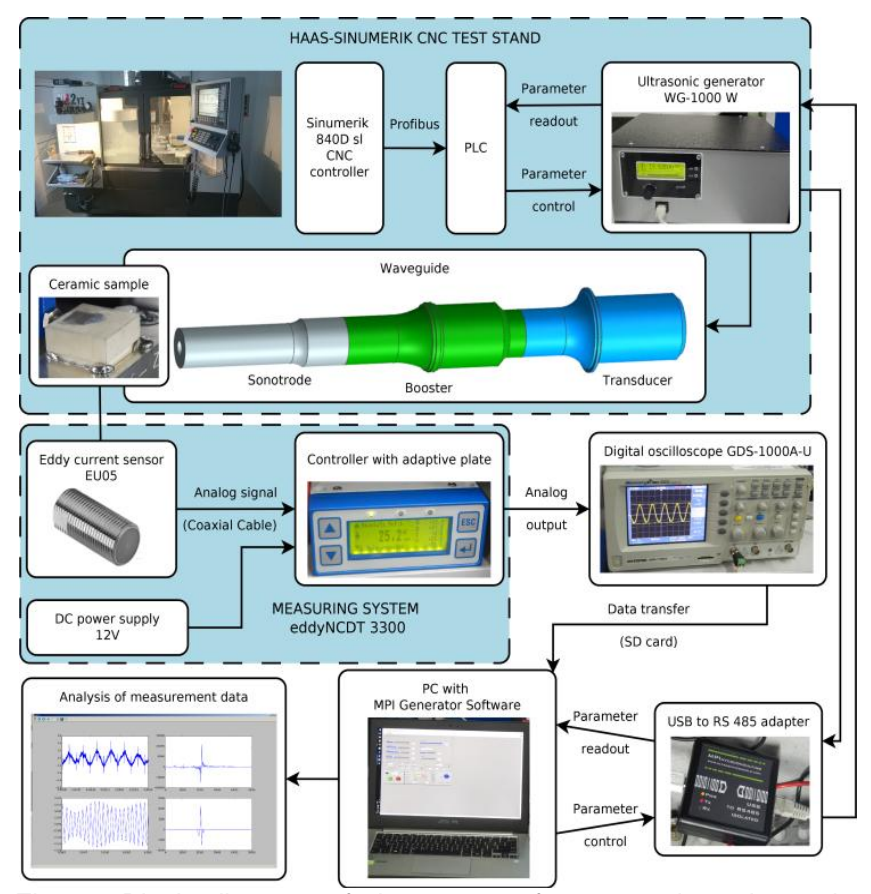

Fig. 4. Block diagram of the system for measuring ultrasonic vibration amplitude [4]

The raw signal is filtered by a bandpass filter with a frequency of $\pm 10 \%$ from $20 \mathrm{kHz}$ to determine the vibration amplitude. To determine their frequency, from the filtered signal an additional Fast Fourier Transform is performed [4].

\section{System for measuring surface roughness}

In surface roughness tests, direct linear contact measurement method was used. Initially, the basis of the measurement system was the Surtronic 3+ profilometer from Taylor-Hobson with the TalyProfile Lite software [4]. 
However - due to the time-consuming manual recording, processing and analysing of measurements from the level of software provided by the manufacturer - a different approach was developed at the modification stage of the test stand. For surface roughness measurements the MarSurf PS 10 profilometer was used with with an original application program automating the process of recording, naming, processing and analysing of registered profiles as well as the values of roughness parameters (fig. 5).

In addition, a special four-axis mounting holder for the drive unit has been developed, allowing the appropriate setting of the unit in the workspace of the machine tool. Thus, it enables the measurement of surface roughness (both for face and peripheral grinding) in the parallel and perpendicular direction to the feed rate and ensures the repeatability of the positioning of the measuring probe relative to the machined surface.

This results in shortening the time needed to correctly position the probe relative to the measured surface after each machining pass of the grinding wheel. At the same time, it allows to increase the number of profile measurement repetitions.

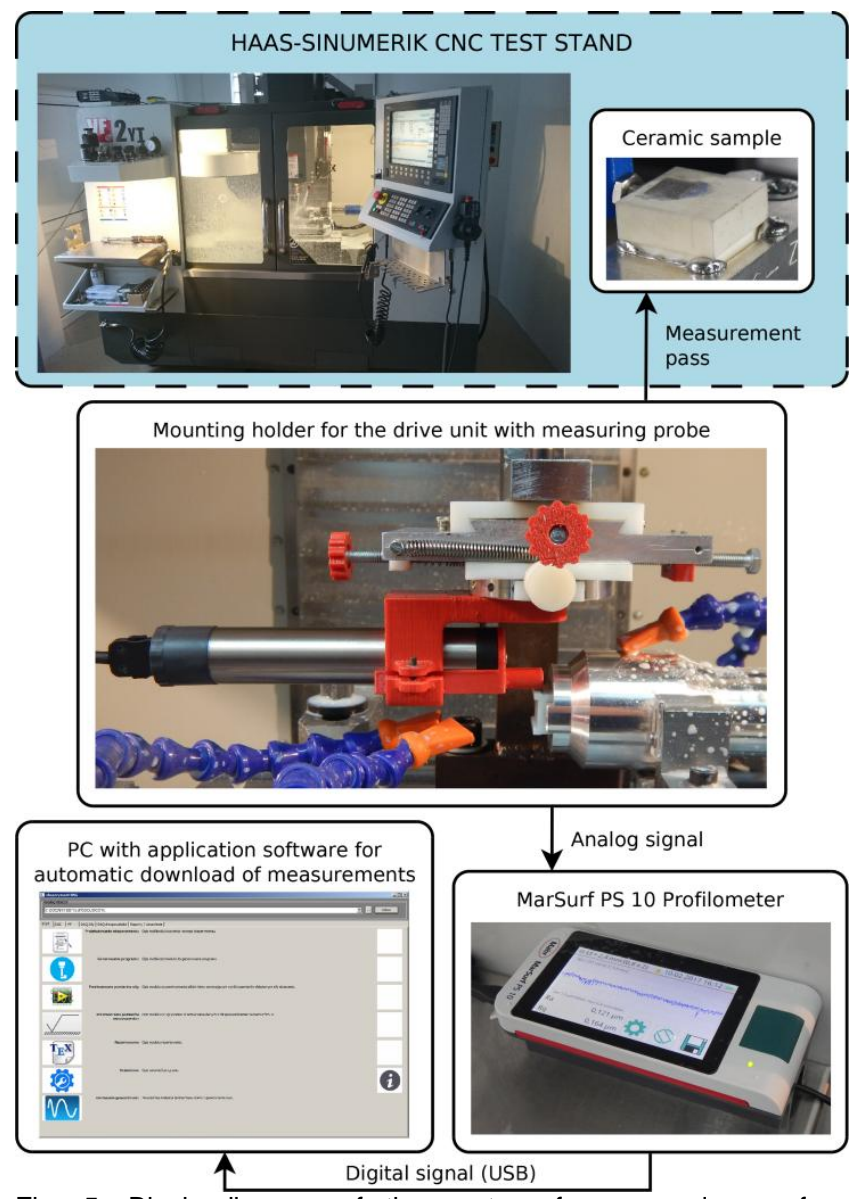

Fig. 5. Block diagram of the system for measuring surface roughness

This had a huge impact on the realization time of the entire experimental design, because the measurements were made each time after the change of technological parameters and the new machining pass of the grinding wheel. After each machining pass, the roughness of the surface was measured several times in the parallel and perpendicular direction to the feed rate. Each registered profile was coded with a unified number, thanks to which it was possible to identify later at which process parameters a given profile was measured.

\section{Conclusions}

As a result of all modifications of the base machine tool, a unique four-axis diagnostic test stand was created to study conventional grinding processes and processes assisted with workpiece oscillations. This test stand allows conducting expanded experimental designs where starting the measurement in LabVIEW SignalExpress and starting the surface roughness measurements after mounting the drive unit to the machine table (during program pause) are the only operating actions to perform. All other actions such as acquiring, transcribing, saving, naming and processing of measuring data are executed by original application program created specifically for the needs of this test stand. To further automate the test stand, it is necessary to introduce solutions including:

- using LabVIEW software to automatically create, name and save TDMS files from individual measurement passes, which will reduce the size of saved files and reduce the time needed to process them. This will translate into the ability to perform in one approach and store data from a larger number of measuring passes.

- using a roughness meter with a wireless drive unit mounted in a tool holder, which will enable automatic positioning of the measuring probe and starting surface roughness measurements (additional signal derived from the PLC) from the level of technological program.

The publication is based on the results of the project entitled "Technology of high performance machining with ultrasonic assistance of geometrically complex ceramic parts", carried out under the Applied Research Programme of the National Centre for Research and Development (PBS2/B6/17/2013).

\section{REFERENCES}

1. Wang Y., Lin B., Wang S., Cao X. "Study on the system matching of ultrasonic vibration assisted grinding for hard and brittle materials processing". International Journal of Machine Tools and Manufacture. 77 (2014): pp. 66-73.

2. Porzycki J., Habrat W., Krok M., Żółkoś M., Sałata M. "Wpływ drgań ultradźwiękowych na siłę i chropowatość powierzchni w procesie szlifowania stopu tytanu Ti6Al4V". Mechanik. 90, 8-9 (2017): pp. 769-771.

3. Wang Y., Lin B., Cao X., Wang S. "An experimental investigation of system matching in ultrasonic vibration assisted grinding for titanium". Journal of Materials Processing Technology. 214, 9 (2014): s. 1871-1878.

4. http://ktwia.prz.edu.pl/projekt-badawczy-pbs2b6172013/ (access: 14.03.2018).

5. http://www.mpi-ultrasonics.com/ (access: 14.03.2018).

6. Krok M., Porzycki J., Żółkoś M. „Wybrane zagadnienia projektowania sonotrod na potrzeby obróbki ubytkowej wspomaganej drganiami ultradźwiękowymi obrabianego przedmiotu". Mechanik. 89, 10 (2016): pp. 1354-1355.

7. https://www.kistler.com/en/ (access: 14.03.2018).

Translation of scientific articles, their computer composition and publishing them on the website www.mechanik.media.pl by original articles in Polish is a task financed from the funds of the Ministry of Science and Higher Education designated for dissemination of science.

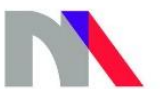

Ministry of Science and Higher Education Republic of Poland 